Syntax Fusion : Jurnal Nasional Indonesia

p-ISSN: -

e-ISSN : 2775-4440

Vol. 1, No. 3, Maret 2021

\title{
JURNAL IT RISK MANAGEMENT ANALISIS RESIKO TEKNOLOGI INFORMASI PADA TOKO PUNTADEWA OUTDOOR
}

\section{Usman dan Andika A. Yudhistira}

Sistem Informasi, STMIK Borneo Internasional

Email: usman.18@stmik-borneo.ac.id,andika_agus.18@stmik-borneo.ac.id

\begin{abstract}
Abstrak
Puntadewa outdoor merupakan sebuah perusahaan yang bergerak dalam bidang penyediaan dan penjualan perlengkapan luar ruangan, toko tersebut sudah menggunakan penerapan SI/TI dalam menunjang aktivitas bisnis yang dijalankan. Toko tersebut menggunakan aplikasi SmartConsole yang digunakan untuk menunjang penjualan, mendata stok barang, serta mendata pengeluaran sehari-hari yang dibutuhkan. Namun dalam dunia manajemen pasti selalu ada kemungkinan risiko yang mungkin dapat terjadi dan dapat mengganggu aktivitas bisnis dalam penggunaan sistem tersebut. Dengan begitu analisis risiko sangat diperlukan terhadap sumber daya SI/TI yang terdapat pada toko tersebut. Dengan menggunakan ISO 31000 diharapkan dapat meminimalisir risiko yang terdapat pada aplikasi SmartConsole. Hasil dari analisis risiko ini berupa analisis kemungkinan risiko, mengelompokkan kemungkinan - kemungkinan risiko berdasarkan dampak nya sehingga menghasilkan usulan tindakan risiko terhadap kemungkinan risiko yang terdapat pada aplikasi SmartConsole, dengan begitu toko tersebut dapat memperlakukan kemungkinan risiko yang ada sesuai dengan prioritas level risikonya dan dapat mencegah serta meminimalisir sehinga tidak mengganggu aktivitas bisnis.
\end{abstract}

Kata Kunci: ISO 31000, analisis risiko, manajemen risiko

\section{Pendahuluan}

Perkembangan teknologi saat ini sangat cepat dan pesat sehingga teknologi menjadi kebutuhan yang sangat intim dalam kehidupan sehari hari terutama dalam dunia bisnis. Teknologi mempunyai peranan yang sangat penting bagi kemajuan sebuah organisasi atau perusahaan untuk dapat bersaing dengan para kompetitornya, terlebih lagi dengan mengoptimalkan pemanfaatkan pengelolaan SI/TI yang baik bagi organisasi atau perusahaan akan menjadikan sebuah organisasi atau perusahaan menjadi lebih efektif dan efesien dalam menjalankan setiap proses bisnis yang ada 
di dalam sebuah organisasi atau perusahaan tersebut. Tidak sedikit organisasi atau perusahaan yang rela mengeluarkan dana yang sangat besar untuk investasi sistem informasi tersebut. Bagi perusahaan yang sukses, mereka pasti menyadari pentingnya manfaat dari SI/TI dan menggunakan SI/TI untuk mendorong (drive) nilai-nilai stakeholder (stakeholder value), Serta menyadari dan melakukanpengelolaan risiko (risk management) terhadap risiko-risiko yang terkait dengan perencanaan dan implementasi SI.

Pengelolaan SI/TI di suatu perusahaan memang penting begitu pula dengan Toko Punta dewa outdoor, Toko perlengkapan luar ruangan yang sudah mengoptimalkan pengelolaan SI/TI di setiap aktifitas manajemen perusahaanya, hal ini dapat dibuktikan dengan adanya Aplikasi SmartConsole. Namun tidak dapat dipungkiri walaupun pengelolaan SI/TI di Toko Punta dewa outdoor sudah optimal, pasti memiliki beberapa kemungkinan ancaman dan risiko yang dapat mengganggu aktivitas proses bisnis yang berjalan terutama masih dapat dilihat secara visual dengan jelas terdapat beberapa risiko di perusahaan yang belum mendapatkan perlakuan risikoseperti Human Error, Overheat, dan Server Down sehingga diperlukan analisis dan evaluasi manajemen risiko terhadap Toko Punta dewa outdoor dengan mengidentifikasi kemungkin risiko dan potensial risiko yang ada, seberapa besar dampak dari risiko yang mungkin terjadi, penilaian dan evaluasi risiko serta apa yang harus dilakukan untuk mengantisipasi risiko dan permasalahan yang ada. Oleh karena itu diperlukan tindakan untuk mengelola risiko yang ada, tindakan mengelola risiko ini telah diatur dalam ISO 31000:2018 tentang risk management. Manajemen risiko adalah upaya manajemen untuk mengendalikan risiko kegiatan operasional perusahaan dengan melakukan analisis risiko, evaluasi risiko dan rencana mitigasinya.

Dalam hal ini tentang analisis risiko teknologi informasi aplikasi SmartConsoledi Toko Punta dewa outdoor dengan pendekatan menggunakan metode ISO 31000:2018. Pada bulan Februari 2018, Organisasi Standar Nasional (ISO) memperkenalkan ISO 31000:2018 kepada public. ISO ini berisikan mengenai Standar Manajemen Risiko. Dengan diterbitkannya ISO 31000 versi terbaru ini maka diharapkan dapat menggantikan standar yang banyak berbeda yang saat ini banyak digunakan perusahaan. ISO 31000:2018 merupakan pedoman standar, instruksi, dan tuntutan bagi sebuah organisasi atau perusahaan untuk membangun sebuah pondasi dan kerangka kerja bagi suatu program manajemen risiko. Pondasi tersebut meliputi aturan, tujuan, dan komitmen untuk membangun suatu program manajemen risiko yang komprehensif. Kerangka kerja meliputi perencanaan, akuntabilitas dari para karyawan, proses dan aktivitas yang digunakan untuk mengelola risiko dalam kinerja perusahaan. Untuk mengelola risiko di Toko Punta dewa outdoor diperlukan risk assessment yang diatur dalam ISO 31000:2018. Analisis risiko menggunakan ISO 31000:2018 dapat terlihat risk value atau nilai risiko dengan tiga tingkatan yaitu risiko dengan tingkatan rendah, sedang, dan tinggi. Dengan menggunakan metode ISO 31000:2018 dimana standar dari metode ini memiliki pandangan yang lebih luas dan 
dapat diterapkan di berbagai ruang lingkup organisasi serta lebih konseptual dibandingkan standar lainya.

Fokus dari metode penilitian ini adalah untuk melakukan identifikasi dari beberapa asset teknologi informasi di Toko Punta dewa outdoor dan mengidentifikasi kemungkinan-kemungkinan risiko yang ada, berapa besar dampak yang ditimbulkan risiko tersebut, serta memberikan rekomendasi kepada Punta dewa outdoor terhadap risiko-risiko yang ada maupun risiko-risiko yang sewaktu-waktu bisa muncul. Dengan begitu kinerja dari aktivitas SI/TI maupun proses bisnis di Punta dewa outdoor dapat dioptimalkan oleh pihak organisasi atau perusahaan.Dalam dunia Manajemen, setiap hal yang dijalankan dalam suatu organisasi atau perusahaan pasti selalu diiringi dengan ancaman dan risiko. Risiko selalu membayangi setiap kegiatan yang dijalani untuk menghambat organisasi atau perusahaan untuk mencapai tujuan maupun visi dan misi mereka, maka dari itu diperlukan suatu pengendalian risiko agar mampu membantu suatu organisasi atau perusahaan untuk menangani setiap risiko yang ada dan mampu mewujudkan tujuan dari organisasi atau perusahaan tersebut.Penelitian sebelumnya yang membahas pula tentang ISO 31000 dilakukan oleh Andi Novia Rilyani dengan judul "Analisis Risiko Teknologi Informasi Berbasis Risk Management Menggunakan ISO 31000" pada tahun 2015. Penelitian ini berfokus pada i-Gracias(Integrated Academic Information System), yaitu sebuah aplikasi yang diakses oleh dosen, mahasiswa, dan staf yang ada di Telkom University. Pada penelitian tersebut membahas tentang analisis risiko mengenai aset-aset yang berhubungan dengan sistem i-Graciasdilihat dari sisi Teknologi dan Infrastrukturnya. Dalam penelitian ini mendapatkan hasil bahwa risiko yang memiliki nilai risiko paling tinggi adalah Database crash. Sedangkan yang berada pada kuadran risiko menengah terdapat 30 risiko dan yang berada pada kuadran risiko rendah terdapat 12 risiko. Penanganan risiko difokuskan pada aset yang memiliki risiko tinggi dengan mengidentifikasi penyebab dan mencari solusi yang tepat.

\section{Metode Penelitian}

Penilitian di Toko Puntadewa Outdoor ini tentang manajemen risiko menggunakan framework ISO 31000:2018. Dimana ISO 31000:2018 memiliki prinsip-prinsip dan pedoman untuk manajemen risiko yang diakui secara internasional. Manajemen Risiko merupakan proses mengidentifikasi risiko, menganalisis serta mengevaluasi risiko yang dimana mampu untuk membentuk suatu strategi untuk mengelola risiko pada aplikasi Smart Console yang ada di Punta Dewa Outdoor. ISO 31000 adalah panduan penerapan risiko yang terdiri atas tiga elemen: prinsip (principle), kerangka kerja (framework), dan proses (process). Prinsip manajemen risiko adalah dasar praktik atau filosofi manajemen risiko. Kerangka kerja adalah pengaturan sistem manajemen risiko secara terstruktur dan sistematis di seluruh organisasi. Proses adalah aktivitas pengelolaan risiko yang berurutan dan saling terkait. Secara umum, ISO 31000:2018 menyederhanakan versi 2009. Hal itu langsung terlihat antara lain dari nama yang berubah dari "principles and guidelines" 
menjadi hanya "guidelines" serta dari jumlah halaman yang menyusut dari 24 halaman menjadi 16 halaman. Diagram yang menggambarkan hubungan prinsip, kerangka kerja, dan proses manajemen proses pun berubah. Pada versi 2009, prinsip, kerangka kerja, dan proses digambarkan sebagai rangkaian unsur yang berurutan, sedangkan pada versi 2018 ketiga bagian ini digambarkan sebagai sistem terbuka yang saling berkaitan.

Pada penelitian ini penulis mengambil salah satu metode untuk manajemen risiko yang sesuai untuk penanganan permasalahan diatas. Metode yang dipilih yaitu ISO 31000 yang dapat digunakan untuk organisasi, perusahaan publik, perusahaan swasta, organisasi nirlaba, kelompok, ataupun perseorangan. Standar ini digunakan digunakan selama masa hidup organisasi dan untuk berbagai kegiatan, proses, fungsi, proyek, produk, jasa, aset, operasi dan pengambilan keputusan. Terdapat lima kegiatan risiko yang termasuk dalam proses manajemen risiko yaitu komunikasi dan konsultasi, menentukan konteks, assesment risiko, perlakuan risiko dan monitoring serta review. Identifikasi risiko, analisis risiko dan evaluasi risiko ketiga hal tersebut termasuk dalam bagian asessment risiko.

Identifikasi Risiko (Risk Identification) Identifikasi pada penelitian ini menggunakan wawancara langsung dengan pihak yang bertanggung jawab yang mencakup penilaian berdasarkan pengalaman dan pencatatan. Berikut ini adalah proses identifikasi risiko:

a) Identifikasi teknologi informasi yang dimiliki oleh organisasi

b) Identifikasi ancaman pada setiap teknologi informasi

c) Identifikasi kemungkinan risiko yang diakibatkan oleh adanya ancaman

d) Identifikasi dampak yang akan diterima oleh organisasi tersebut

Analisis Risiko (Risk Analiysis) Penelitian ini menerapkan analisis risiko secara kualitatif. Analisis kualitatif merupakan analisis yang cepat dan relatif mudah untuk digunakan untuk jangkauan identifikasi dampak (impact) dan kemungkinan (likelihood) yang luas yang dapat digunakan sebagai bahan evaluasi pemeringkatan risiko. Analisa risiko secara kualitatif merupakan proses penentuan prioritas untuk analisis atau tindakan respon yang lebih jauh dengan mengukur dan mengkombinasikan probabilitas terjadinya risiko serta dampak dari risiko tersebut [10]. Analisa risiko kualitiatif dianggap sebagai tahapan yang paling efektif dan hemat biaya sebab melalui analisa ini, organisasi atau perusahaan dapat melakukan improvisasi terhadap performansi proyek dengan berfokus pada risiko yang memiliki tingkat prioritas tinggi (highpriority risk). Prioritas risiko ini pada akhirnya dapat digunakan pula sebagai dasar dalam melakukan analisa risiko kuantitatif apabila diperlukan. Ketika peluang atau probabilitas (likelihood) serta dampak telah diidentifikasi, maka kemudian akan dilakukan evaluasi untuk mengetahui risiko yang menjadi prioritas untuk ditangani terlebih dahulu [11]. 


\section{Hasil Dan Pembahasan}

\section{Penilaian Risiko}

Pada tahap ini merupakan tahap penilaian risiko Puntadewa Outdoor . Pada Proses penilaian risiko aplikasi SmartConsole ini terdiri dari 3 tahap yaitu :

1.Identifikasi risiko (risk identification),

2.analisis risiko (risk analysis),

3.evaluasi risiko (risk evaluation).

\section{Identifikasi Risiko}

\section{Identifikasi Aset}

Pada tahap pertama, dilakukan identifikasi aset yang berhubungan dengan aplikasi SmartConsole seperti aset data, aset perangkat lunak (Software), dan aset perangkat keras (Hardware). Dan dalam identifikasi ini mewawancarai Pemilik Puntadewa Outdoor dan Staff IT atau bagian yang mengurusi sistem SmartConsole. Pada tahap ini memfokuskan pada aset data, software dan hardware-nya.

Tabel 1. Identifikasi Aset

\begin{tabular}{cc}
\hline Komponen system informasi & Informasi data \\
\hline Data & Data barang, data supplier, data karyawan \\
\hline Software & Aplikasi Smart Console \\
\hline Hardware & Personal computer, database server
\end{tabular}

Pada tabel 1 memperlihatkan aset dari komponen sistem informasi yang berupa data, software, dan hardware yang mendukung perkembangan aplikasi SmartConsole.

2. Identifikasi Kemungkinan Risiko

Setelah melakukan identifikasi aset yang menghasilkan informasi dari data, software, dan hardware yang berkaitan dengan aplikasi SmartConsole. Selanjutnya perlu dilakukan identifikasi kemungkinan risiko yang dapat menjadi ancaman bagi aplikasi SmartConsole. Kemungkinan risiko dapat dikelompokkan berdasarkan 3 faktor yaitu; faktor alam/lingkungan, faktor manusia dan faktor system dan infrastruktur. Yang bisa dilihat pada tabel 2. dibawah ini.

Tabel 2. Identifikasi Kemungkinan Risiko

\begin{tabular}{ccc}
\hline Faktor & Id & Kemungkinan resiko \\
\hline Alam & R1 & Banjir \\
& R2 & Kebakaran \\
& R3 & Petir \\
& & Human Error \\
\hline Manusia & R4 & Penyalahgunaan hak akses \\
& R5 & Pencurian dan kebocoran data \\
& R6 & Pencurian hardware \\
& R7 & Hacking \\
& R8 & User Interface yang sulit dipahami \\
& &
\end{tabular}




\section{R9 Pegawai baru yang belum mengerti betul alur kerja sistem}

\section{R10}

\begin{tabular}{lll}
\hline Sistem Dan & R11 & Koneksi jaringan yang buruk Kerusakan hardware \\
Infrastrukture & R12 & Server down \\
& R13 & Data korup \\
R14 & Overheat \\
R15 & Touble Backup \\
R16 & Sistem error \\
R17 & Listrik padam \\
R18 &
\end{tabular}

Dari tahapan identifikasi risiko, ditemukan ada 18 kemungkinan - kemungkinan risiko yang berasal dari ketiga faktor tadi yaitu: alam/lingkungan, manusia, system dan infrastruktur.

\section{Analisis Risiko}

Selanjutnya masuk dalam tahap analisis risiko. Pada tahap ini dilakukan penilaian terhadap kemungkinan-kemungkinan risiko pada tahap identifikasi risiko sebelumnya, dengan menggunakan tabel kriteria Likelihood. Pada tabel Likehood terdapat 5 kriteria yang berdasarkan frekuensi kejadian kemungkinan risiko yang akan terjadi terjadi.

Tabel 4. Kriteria Likelihood

\begin{tabular}{llll}
\hline Nilai & Likelihood & Deskripsi & Frekuensi Kejadian \\
\hline 1 & Kriteria & Resiko tersebut hamper tidak pernah terjadi & >2tahun \\
& Rare & & \\
\hline 2 & Unlikely & Risiko tersebut jarang terjadi & 1-2 Tahun \\
\hline 3 & Possible & Risiko tersebut kadang terjadi & 7-12 Bulan \\
\hline 4 & Likely & Risiko tersebut sering terjadi & 4-6 Bulan \\
\hline 5 & Certain & Risiko tersebut pasti terjadi & 1-3 Bulan \\
\hline
\end{tabular}

Kemudian pada tabel 5 dibawah ini merupakan tabel nilai impact atau dampak yang terjadi dari kemungkinan risiko di Toko Puntadewa Outdoor. Pada tabel penilaian dampak ini dikelompokkan kedalam 5 kriteria dan dikelompokkan berdasarkan mulai dari dampak yang paling tidak berpengaruh sampai dampak yang paling berpengaruh. 
Tabel 5. Kriteria Impact

\begin{tabular}{lll}
\hline Nilai & Impact & Keterangan \\
\hline 1 & Kriteria Insignificant & $\begin{array}{l}\text { Tidak mengganggu } \\
\text { aktifitas }\end{array}$ \\
\hline 2 & Minor & $\begin{array}{l}\text { Aktifitas perusahaan sedikit } \\
\text { terhambat }\end{array}$ \\
\hline 3 & Moderate & $\begin{array}{l}\text { Menyebabkan gangguan } \\
\text { pada proses bisnis }\end{array}$ \\
& & Menghambat hamper \\
& Major & seluruh aktifitas \\
\hline 5 & Catasirophic & Aktifitas perusahaan \\
& & berhenti \\
\hline
\end{tabular}

Tabel 6. Penilaian Likelihood dan Impact

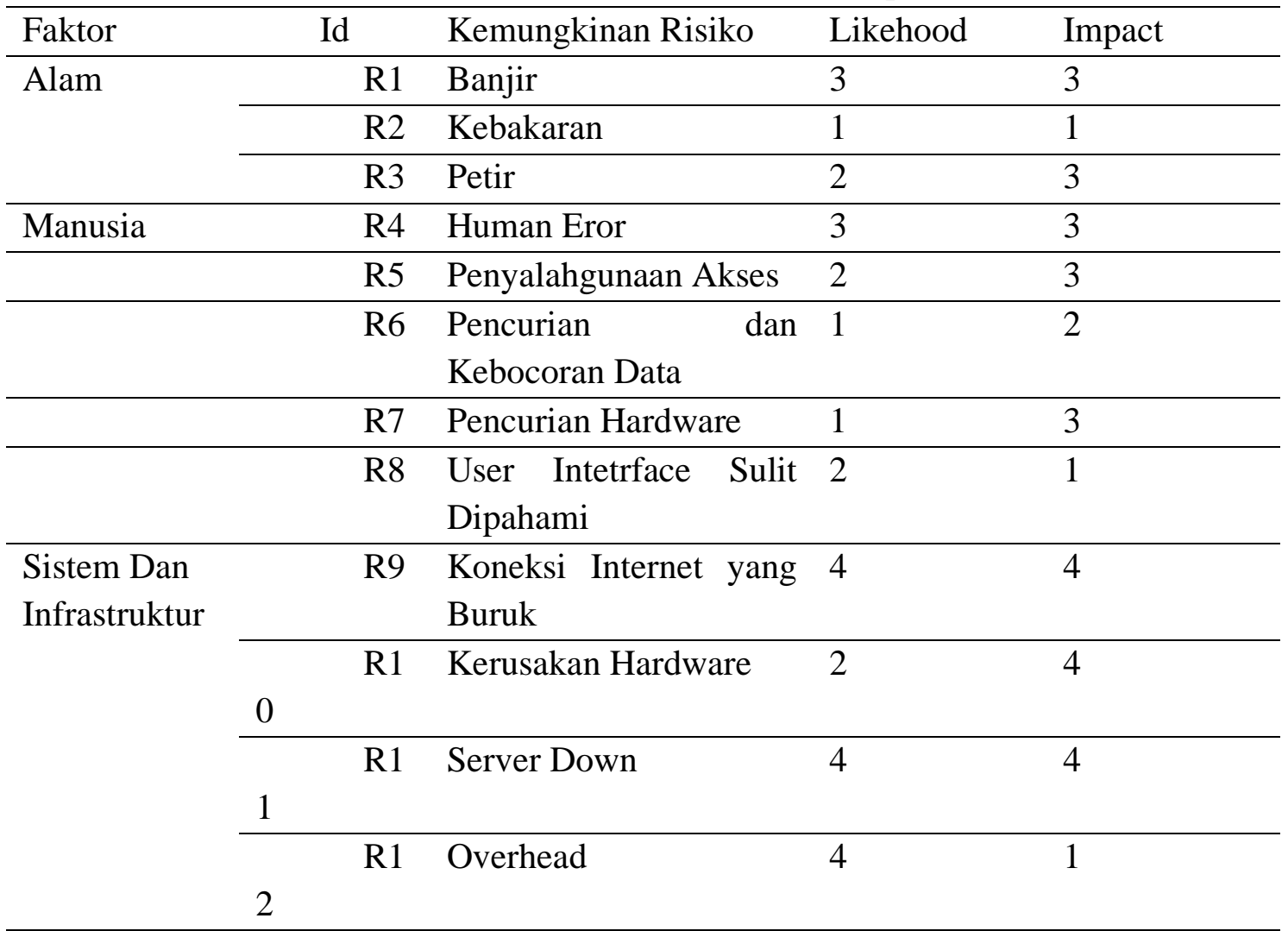

Dari tabel 6 diatas dapat menemukan nilai dari kemungkinan risiko yang ada pada tabel Likelihood dan Impact. Setelah menemukan nilai dari Likelihood dan Impact, kemudian masuk pada tahap evaluasi risiko.

3. Evaluasi Risiko 
Pada tahapan terakhir yaitu evaluasi risiko akan dilakukan proses evaluasi risiko dari kemungkinan - kemungkinan risiko yang sudah di analisis pada tahapan sebelumnya. Dari hasil analisis tersebut akan dimasukkan ke dalam matrix evaluasi risiko berdasarkan pedoman yang ada di dalam kerangka kerja ISO 31000. Matrix evaluasi dibedakan menjadi 3 level risiko yaitu : Low, Medium, dan High.

\begin{tabular}{|l|l|l|l|l|l|l|l|}
\hline & Certain & 5 & Medium & Medium & High & High & High \\
\cline { 2 - 8 } & Likely & 4 & Medium & Medium & Medium & High & High \\
\cline { 2 - 7 } & Possible & 3 & Low & Medium & Medium & Medium & High \\
\cline { 2 - 7 } & Unlikely & 2 & Low & Low & Low & Medium & Medium \\
\cline { 2 - 7 } & Rare & 1 & Low & Low & Low & Medium & Medium \\
\cline { 2 - 7 } & Impact & 1 & 2 & 3 & 4 & 5 \\
\cline { 3 - 6 } & & Insigfiact & Minor & Moderate & Major & Catastrophic \\
\hline
\end{tabular}

Pada tabel 7 menjelaskan tentang rasio pengelompokan berdasarkan level risiko dari yang tertinggi (high), hingga terendah (low). Tahap selanjutnya yaitu memasukkan setiap identitas kemungkinan risiko kedalam matrix evaluasi risiko sesuai dengan kriteria Likelihood dan kriteria Impact

Tabel 8. Matrix Evaluasi Risiko Berdasarkan Likelihood dan Impact

\begin{tabular}{|c|c|c|c|c|c|c|c|}
\hline \multirow{7}{*}{ ' } & Certain & 5 & & & & & \\
\hline & Likely & 4 & R12 & & & $\begin{array}{l}\text { R9 } \\
\text { R11 }\end{array}$ & \\
\hline & Possible & 3 & & & & & \\
\hline & Unlikely & 2 & R8 & & & R10 & \\
\hline & Rare & 1 & R2 & R6 & $\begin{array}{l}\text { R1 } \\
\text { R4 }\end{array}$ & & \\
\hline & \multirow[t]{2}{*}{ Impact } & & 1 & 2 & 3 & 4 & 5 \\
\hline & & & Insigfiact & Minor & Moderate & Major & Catastrophic \\
\hline
\end{tabular}

Berdasarkan Likelihood dan Impact beberapa kemungkinan risiko dapat dikategorikan dengan rasio yang sesuai seperti pada tabel 8 . Setelah memasukan kemungkinan risiko ke dalam matrix evaluasi berdasarkan Likelihood dan Impact, pada tahapan berikutnya akan di dikelompokkan 20 kemungkinan risiko diatas kedalam tingkatan level high, medium dan low.

Tabel 9. Pengelompokkan Risiko Berdasarkan Tingkatan

\begin{tabular}{|l|l|l|l|l|}
\hline ID & $\begin{array}{l}\text { Kemungkinan } \\
\text { Risiko }\end{array}$ & Likehood & Impact & Risk Level \\
\hline R9 & $\begin{array}{l}\text { Koneksi Internet } \\
\text { yang Buruk }\end{array}$ & 4 & 4 & High \\
\hline R11 & Server Down & 4 & 4 & High \\
\hline R10 & $\begin{array}{l}\text { Kerusakan } \\
\text { Hardware }\end{array}$ & 4 & 1 & Medium \\
\hline R12 & Overhead & 2 & 4 & Medium \\
\hline R1 & Banjir & 1 & 3 & Low \\
\hline R2 & Kebakaran & 1 & 1 & Low \\
\hline R4 & Human Eror & 1 & 3 & Low \\
\hline R6 & $\begin{array}{l}\text { Pencurian dan } \\
\text { Kebocoran Data }\end{array}$ & 1 & 2 & Low \\
\hline R8 & $\begin{array}{l}\text { User Intetrface } \\
\text { Sulit Dipaham }\end{array}$ & 2 & 1 & Low \\
\hline
\end{tabular}




\section{Perlakuan Risiko}

Setelah melakukan proses identifikasi risiko mengenai asset yang berada dalam lingkungan aplikasi SmartConsole, maka selanjutnya akan dilakukan tahap Risk Treatment atau perlakuan risiko. Dalam tahap ini memberikan tindakan risiko terhadap kemungkinan risiko yang sudah di kelompokkan berdasarkan risk level pada tabel 9.

Dalam tabel 10 ini diharapkan dapat meminimalisir kemungkinan risiko yang dapat terjadi bagi aplikasi SmartConsole yang dimiliki Toko Puntadewa Outdoor.

\begin{tabular}{|c|c|c|c|}
\hline ID & Kemungkinan Risiko & Risk Level & Tindakan \\
\hline $\mathrm{Rg}$ & $\begin{array}{l}\text { Koneksi Internet yang } \\
\text { Buruk }\end{array}$ & High & $\begin{array}{l}\text { Mengganti jaringan } \\
\text { ISP (Internet Service } \\
\text { Proider) yang baru, } \\
\text { atau mengingkatkan } \\
\text { kecepatan pada } \\
\text { internet toko. }\end{array}$ \\
\hline R11 & Server Down & High & $\begin{array}{l}\text { Melakukan } \\
\text { pengecekan secara } \\
\text { berskala pada } \\
\text { database }\end{array}$ \\
\hline R10 & Kerusakan Hardware & Medium & $\begin{array}{l}\text { Mendaftarkan } \\
\text { asuransi untuk aset- } \\
\text { aset berharga. }\end{array}$ \\
\hline R12 & Overhead & Medium & $\begin{array}{l}\text { Menambah fan pada } \\
\text { setiap hardware }\end{array}$ \\
\hline Rl & Banjir & Low & $\begin{array}{l}\text { Meletakkan alat-alat } \\
\text { penting yang mudah } \\
\text { rusak jika terkena air } \\
\text { ke tempat yang lebih } \\
\text { tinggi }\end{array}$ \\
\hline $\mathrm{R} 2$ & Kebakaran & Low & $\begin{array}{l}\text { Menyiapkan alat } \\
\text { pemadam kebakarak }\end{array}$ \\
\hline R4 & Human Eror & Low & $\begin{array}{l}\text { Melakukan training } \\
\text { dan pengawasan pada } \\
\text { user }\end{array}$ \\
\hline R6 & $\begin{array}{l}\text { Pepcuriandan dan } \\
\text { Kedabelahtbaterlaku } \\
\text { KESIMPULAN DAI }\end{array}$ & $\begin{array}{l}\text { Low } \\
\text { n risiko } \\
\text { J SARAN }\end{array}$ & $\begin{array}{l}\text { Memasang CCTV, } \\
\text { Alarm, alat sensor } \\
\text { pada setiap ruangan, } \\
\text { dan memasang } \\
\text { password pada setiap } \\
\text { komputer }\end{array}$ \\
\hline R8 & $\begin{array}{l}\text { User Intetrface Sulit } \\
\text { Dipaham }\end{array}$ & Low & $\begin{array}{l}\text { Mengubah tampilan } \\
\text { user interface }\end{array}$ \\
\hline
\end{tabular}

Berdasarkan penelitian analisis risiko SI/TI menggunakan ISO 31000:2018 pada aplikasi SmartConsole yang dimiliki Toko Puntadewa Outdoor mulai dari tahapan penilaian risiko, identifikasi risiko, analisis risiko, evaluasi risiko, hingga tahap perlakukan risiko. Dari tahapan - tahapan tersebut, analisis risiko ini mendapatkan 12 kemungkinan risiko yang dapat sewaktu-waktu bisa menganggu kinerja dari aplikasi 
SmartConsole maupun mengganggu proses bisnis yang terdapat di Toko Puntadewa Outdoor Penajam Paser Utara. Terdapat 2 kemungkinan risiko dengan tingkat High meliputi koneksi jaringan yang buruk dan server down. Kemudian terdapat 2 kemungkinan risiko dengan tingkat Medium meliputi kerusakan hardware dan overhead. Dan juga terdapat 8 kemungkinan risiko dengan tingkat Low yang meliputi Banjir, Kebakaran, Human Eror, Pencurian dan Kebocoran Data. Setelah penelitian ini dilakukan, diharapkan penelitian ini dapat digunakan Toko Puntadewa Outdoor Penajam Paser Utara sebagai pedoman atau kebijakan untuk meminimalisir kemungkinan kemungkinan risiko yang dapat terjadi dengan menggunakan usulan tindakan risiko yang sudah tersedia dalam tabel 10 .

\section{Kesimpulan}

Hasil dari analisis risiko ini berupa analisis kemungkinan risiko, mengelompokkan kemungkinan - kemungkinan risiko berdasarkan dampak nya sehingga menghasilkan usulan tindakan risiko terhadap kemungkinan risiko yang terdapat pada aplikasi SmartConsole, dengan begitu toko tersebut dapat memperlakukan kemungkinan risiko yang ada sesuai dengan prioritas level risikonya dan dapat mencegah serta meminimalisir sehinga tidak mengganggu aktivitas bisnis 


\section{Biliografi}

A. R. Tampubolon and Suhardi, "Manajemen Risiko Teknologi Informasi Menggunakan Framework ISO 31000: 2009 Studi Kasus: Pembobolan ATM BCA Tahun 2010," J. Telemat., vol. 7, no. 2, pp. 1-10, 2011.

H. T. I. Driantami, Suprapto, and A. R. Perdanakusuma, "Analisis Risiko Teknologi Informasi Menggunakan ISO 31000 (Studi kasus: Sistem Penjualan PT Matahari Department Store Cabang Malang Town Square)," J. Pengemb. Teknol. Inf. dan Ilmu Komput., vol. 2, no. 11, pp. 4991-4998, 2018.

D. E. Adi and N. Susanto, "Analisis Manajemen Risiko Aktivitas Pengadaan pada Percetakan Surat Kabar,” J. Metris, vol. 18, pp. 113-118, 2017.

I. Lanin, "Standar Baru Manajemen Risiko ISO 31000:2018," IBFG Institute, 2018. https://ibfgi.com/risk-management-31000/ (accessed Apr. 12, 2018).

Angraini and I. D. Pertiwi, "Analisa Pengelolaan Risiko Penerapan Teknologi Informasi Menggunakan ISO 31000,” J. Ilm. Rekayasa dan Manaj. Sist. Inf., vol. 3, no. 2, pp. 70-76, 2017,[Online]. Available: http://ejournal.uinsuska.ac.id/index.php/RMSI/article/view/4317.

D. L. Ramadhan, R. Febriansyah, and R. S. Dewi, "Analisis Manajemen Risiko Menggunakan ISO 31000 pada Smart Canteen SMA XYZ,” JURIKOM (Jurnal Ris. Komputer), vol. 7, no. 1, p. 91, 2020, doi: 10.30865/jurikom.v7i1.1791.

A. Novia Rilyani, Y. A. Firdaus W ST, and D. S. Dwi Jatmiko, “Analisis Risiko Teknologi Informasi Berbasis Risk Management Menggunakan ISO 31000 (Studi Kasus: i-Gracias Telkom University) Information Technology Risk Analysis Based On Risk Management Using Iso 31000 (Case Study: i-Gracias Telkom University)," e-Proceeding Eng., vol. 2, no. 2, pp. 6201-6208, 2015.

Rahmawati, A., dan Wijaya, A. (2019). Analisis risiko teknologi informasi menggunakan ISO 31000 pada Aplikasi ITOP. Jurnal SITECH. 2(1), 14-20.

Kurniawan, A. (2012). Audit internal nilai tambah bagi organisasi. Yogyakarta: BPFE. (1), 36-43.

Project Management Institute (2008), A Guide to the Project Management Body of Knowledge (PMBOK Guide) Fourth Edition, Project Management Institute, Pennsylvania 